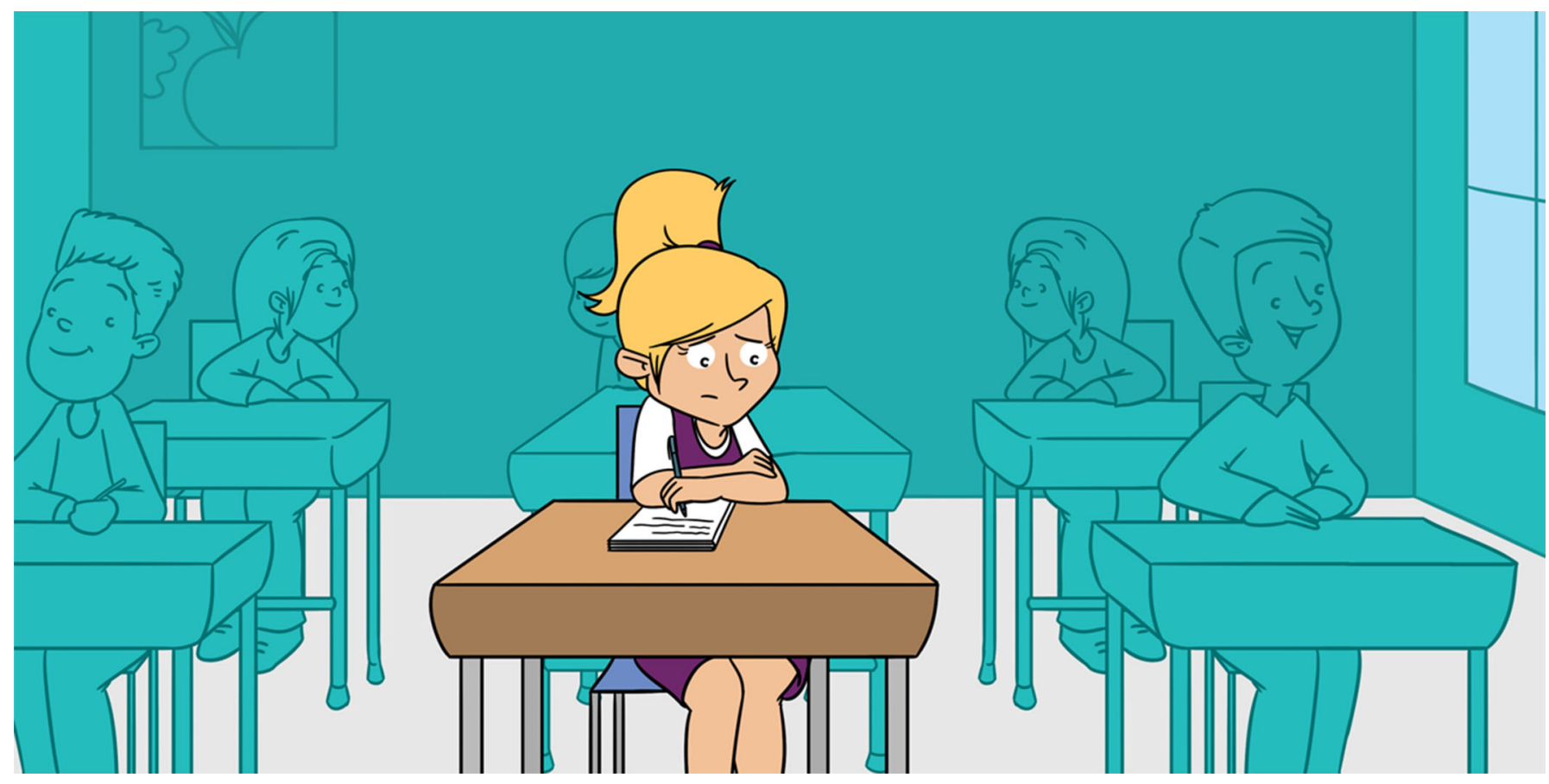

\title{
DO YOU FEEL LIKE YOU BELONG?
}

\section{Kelly-Ann Allen ${ }^{1,2 *}$}

${ }^{1}$ Educational Psychology and Inclusive Education, Faculty of Education, Monash University, Clayton, VIC, Australia

${ }^{2}$ Centre for Positive Psychology, Melbourne Graduate School of Education, The University of Melbourne, Parkville, VIC, Australia

YOUNG REVIEWER:

MATTIA

AGE: 12
People have a natural need to connect and belong. Belonging makes a person feel good and accepted. A sense of belonging, particularly in schools, is important for young people. However, many students do not feel that they belong at their schools. This feeling may only be temporary and can change at any time. Parents, teachers, and other students have vital roles in improving young people's sense of belonging. Other factors that also influence a young person's sense of belonging in school are personal characteristics, mental health, and academic motivation.

\section{WE ALL WANT TO BELONG}

Imagine for just 1 minute that you have found yourself in a room, on your own. There are no windows, there is no furniture, and there are certainly no people. The room is stripped down to nothing. The floor is exposed, the walls are bare. There is nothing in the room but you and the clothes you are wearing. You stop whatever you are doing and try to clear your mind. What is the first thing you think about? 
Chances are you think about someone you know-another person. That is because, when we are seemingly at rest, our brains work in the same way they do when we are engaged in interacting with other people. This occurrence is explained by something called the default mode network [1]. The default mode network is a large brain network that becomes active when our brains are not focused on anything in particular. Researchers now understand that the default mode network can still be active even when we are engaged in other tasks. It enables us to think about others, our self, and our past or future. The default mode network reflects our need to belong and interact with others.

Even though we sometimes want to be alone, most of us strive to connect with other people-to fit in and to belong. Have you ever eaten something you did not like, to avoid offending someone? Perhaps it was your Nana's home-cooked tuna mornay? Have you ever stopped yourself from doing something because you knew that it would be met with judgment or disapproval? Like singing a favorite song out loud when it came through the speakers at your local supermarket? Have you ever been unsure about a particular situation and looked around the room to see what other people were doing? Perhaps it was an activity at school or in a new country you traveled to? The reason why you might have decided to "go with the flow" and hide your real feelings or wants is because of the natural urge to belong and fit in.

\section{SENSE OF}

BELONGING

Feeling of being accepted, included, and part of something.

\section{WHAT IS BELONGING?}

A sense of belonging has been described as one of our most important needs [2]. In fact, belonging means that you feel accepted, included, or a part of something else. People can feel like they belong to a school, a friendship, a sporting group, or even a classroom [3]. And we know two things: belonging feels good, but we tend not to realize this until we miss it. But what does belonging feel like, exactly? It is hard to say, but we know that the feeling of not belonging can feel like physical pain for some people, like jamming your thumb in a car door or burning your finger on a hot stove [4]. Not belonging can be linked to feelings of worthlessness, self-doubt, isolation, and sadness. It can affect your relationships with others and even your grades. Belonging is important and can be experienced differently by different people. Because many young people around the world attend school, schools are a primary place for most young people to feel a sense of belonging [5].

\section{MANY STUDENTS DO NOT FEEL LIKE THEY BELONG AT THEIR SCHOOLS}

If you feel like you do not belong, you are not alone. In fact, if you look around the average classroom, at least one in every three students 
Figure 1

Percentages of students who do not feel a sense of school belonging for the years 2003, 2012, 2015, and 2018. More and more students are not feeling like they belong in school, according to the Organisation for Economic Co-operation and Development (OECD) [6].

\section{PSYCHOSOCIAL}

FUNCTIONING

Ability to perform daily activities and interact with other people.

\section{WELL-BEING}

Refers to the experience of being healthy, happy, and comfortable.

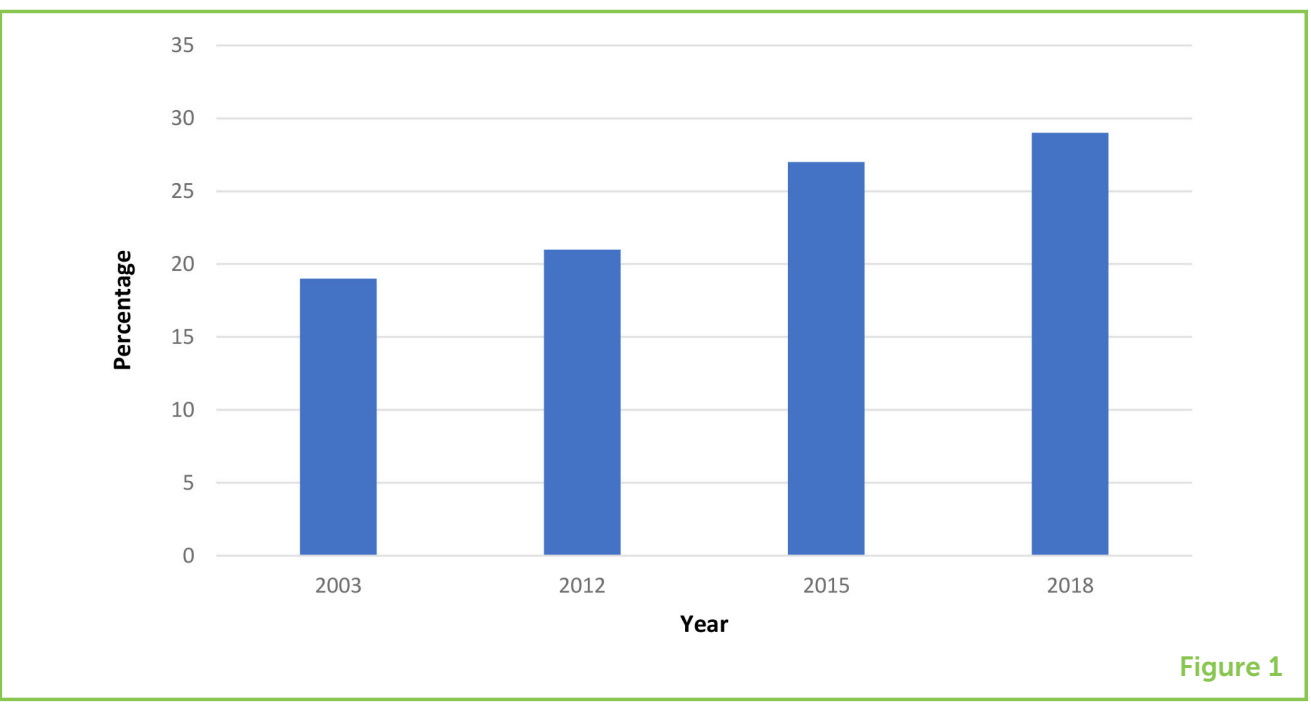

would not feel a sense of belonging [6]. When some researchers asked students if they recently felt like they belonged at their schools, 29\% of them said they did not feel that way, and this percentage has been steadily increasing since 2003 (Figure 1). Feelings of not belonging and loneliness are a part of the spectrum of human emotions. There is nothing wrong with feeling these things. We all move through different waves of belonging, especially at school. Some days we may feel more connected than others. Some days we may feel lonelier than others. Your feelings of belonging may sometimes be high, and sometimes be low, and sometimes they may fall somewhere in between. Belonging is a unique experience and my own research has found that there are a lot of things that can influence it [7]. The main point here, however, is that feelings of not belonging can be temporary. They can be changed.

\section{THE IMPORTANCE OF BELONGING}

When students feel that they belong, they are more likely to get good grades and otherwise perform well in school. A feeling of belonging also positively affects students' psychosocial functioning, meaning their ability to perform daily activities and interact with people around them. Research has found that a sense of belonging is an important factor in students' motivation, and how they cope and learn in school. A feeling of belonging fosters positive attitudes toward learning, improves well-being, and improves your confidence in your ability to do well in school. Additionally, a high sense of belonging is related to less misconduct in school and more positive social relationships [7].

\section{EVERYONE HAS A ROLE IN HELPING OTHER PEOPLE TO BELONG}

There are lots of reasons why other people may not feel like they belong to your group of friends, to your school, or to another 
Figure 2

Rainbow model of school belonging. There are many factors that can influence a young person's sense of belonging, including their personality, social groups and family, school, local community, natural environment, culture, and even the broader issues surrounding the planet, such as climate change. This figure shows that these influential factors can blend together, much like the colors of a rainbow. This figure also shows that a young person's sense of belonging can waiver between high and low. Adapted from Allen and Kern [8].

\section{SCHOOL}

\section{BELONGING}

A sense of affiliation to school that may also involve teachers and peers.

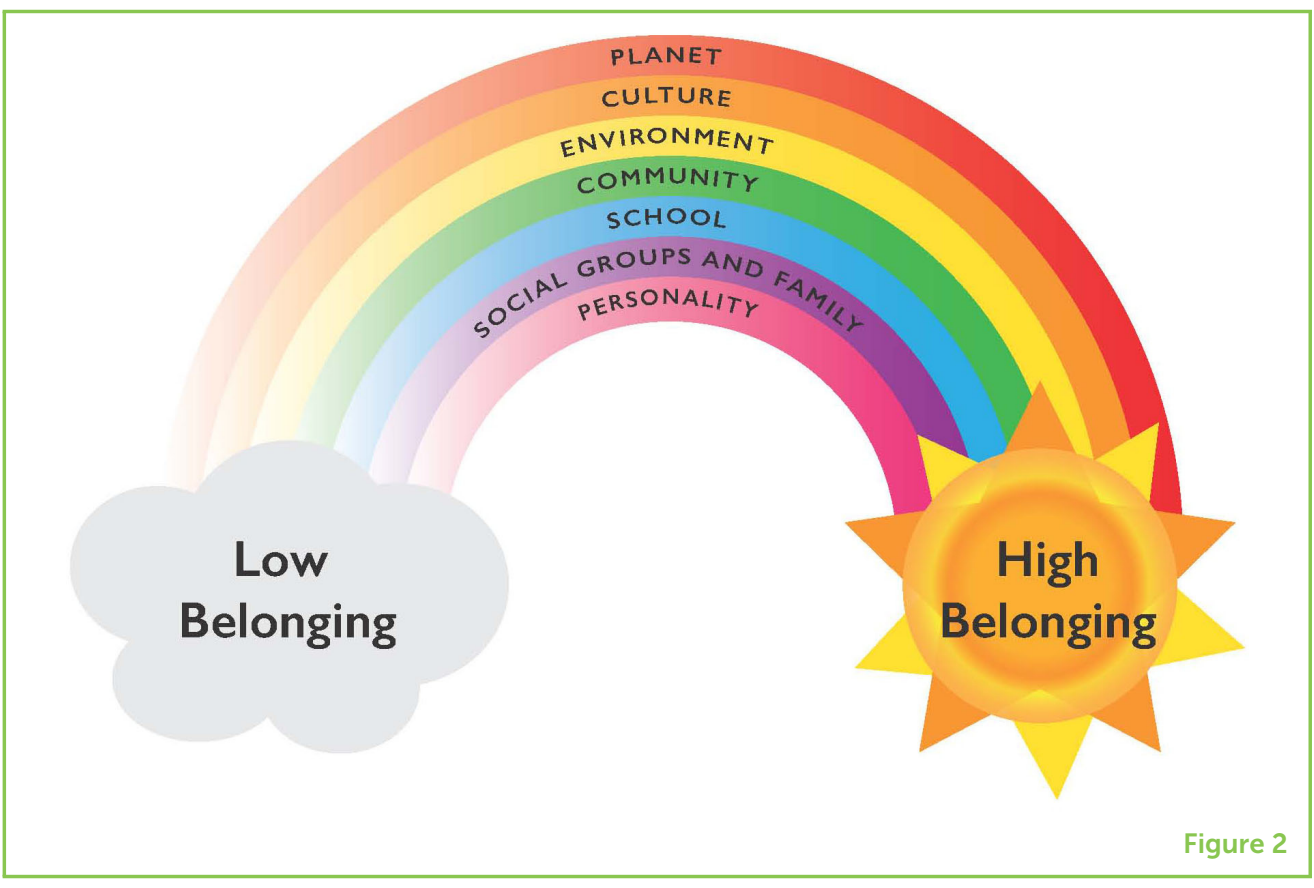

group you may be involved in. It is important to remember that "belongingness can be almost as compelling as the need for food" [2]. That means that nearly everyone you know will want to be included and feel a sense of belonging-even your teachers, parents, and caregivers.

\section{WHAT CAN YOU DO TO HELP OTHERS BELONG?}

Research has found that there are many things that can influence a sense of belonging for young people at school and these things can be found within school and outside of school (Figure 2). Some of the most important factors stem from the relationships young people have with parents, teachers, and other students. Building strong and healthy relationships with the core people in your life will help create a sense of belonging. Young people who feel close to and supported by their friends, in terms of both schoolwork and personal issues, are more likely to feel like they belong at school. One of the most powerful predictors of school belonging is teachers. When young people feel liked and cared for by teachers, and think their teachers are likable and fair, they are more likely to report feelings of school belonging. Young people with parents who support them at school, who have positive conversations with their kids about school, and who take an interest in their kids' education have also been found to feel high levels of school belonging. Parents also have a role to play in helping their kids maintain regular school attendance and participate in school-sanctioned events, which also helps kids have good feelings about school. 
Figure 3

Cookies! Even the adult students in my classes need a reminder that they belong. This cookie was made using a famous quote by Brené Brown.

\section{MENTAL HEALTH}

A state of mental well-being that relates to how a person can cope with stress and be productive.

\section{PERSONAL}

\section{CHARACTERISTICS}

Reflects a person's individual traits, characteristics, and skills.

ACADEMIC MOTIVATION

Desire to perform well in school.

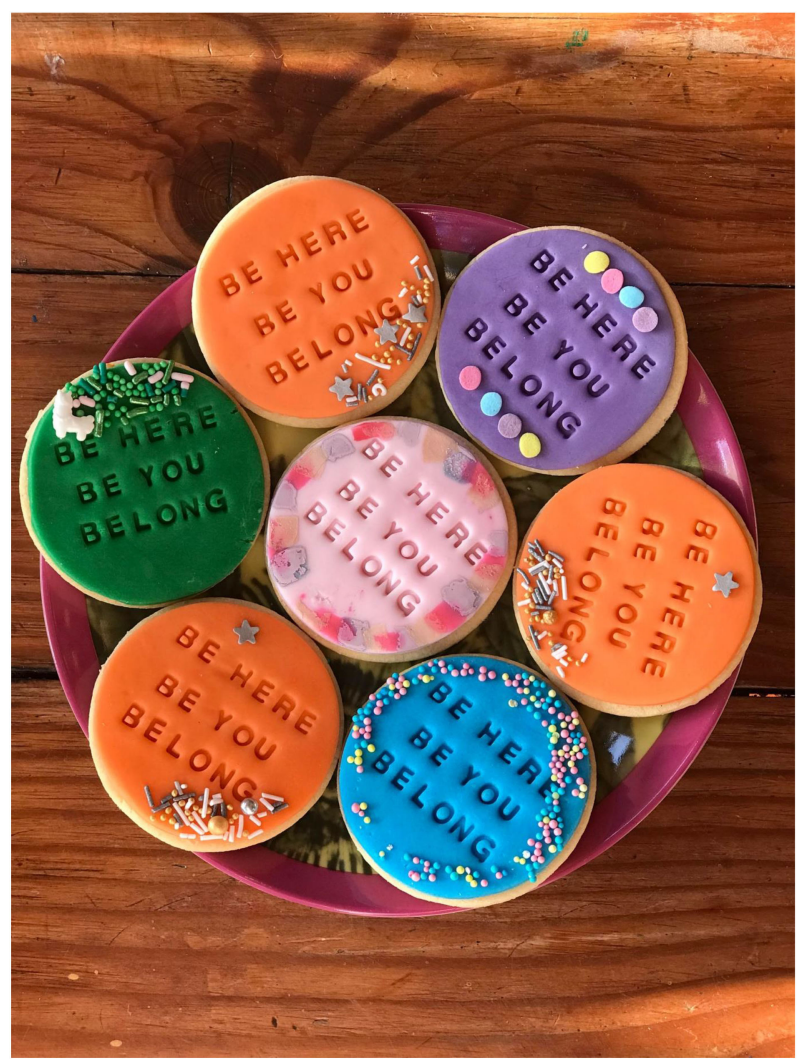

Figure 3

Interestingly though, it is not just other people who help with belonging. You can help with your own sense of belonging as well! Young people who are resilient (able to bounce back from problems), who can cope well with challenges and stress, and who are flexible and adaptable are in a good position to feel a sense of belonging. Young people who are happy and have good mental health are more likely to feel like they belong. And there is one more thing that might surprise you. Those students who are motivated at school, who see a purpose and value in learning, and who have good study habits also feel like they belong at school. To summarize, peers, teachers, parents, mental health, personal characteristics, and academic motivation are some of the building blocks of strong school belonging that can be found in the scientific literature. As I am sure you will agree, we can see from these findings that there are many things that can be done to help improve the sense of belonging for young people.

\section{WHAT CAN SCHOOLS DO TO INCREASE A SENSE OF SCHOOL BELONGING IN STUDENTS?}

We know from our own research that most schools want their students to feel a sense of belonging [7]. Some schools have even made great strides to create an improved sense of belonging in young people. However, there is little research evidence available that has 
examined which programs and interventions are available to schools and whether they work. We do know that teachers who take an interest in getting to know their students, who find similarities with their students, and who are available to support students personally and academically are doing a number of things to support a sense of belonging in their classrooms (Figure 3). Interestingly, a teacher's sense of belonging in school has also been found to predict a student's sense of belonging in school. School leaders who take an interest in the staff's feelings of belonging are also helping students to belong. Creating a culture of belonging is therefore something that everybody has a role in.

\section{ACKNOWLEDGMENTS}

The author wishes to thank Kathryn Kallady for her illustration of the Rainbow Model of School Belonging.

\section{REFERENCES}

1. Li, W., Mai, X., and Liu, C. 2014. The default mode network and social understanding of others: what do brain connectivity studies tell us. Front. Hum. Neurosci. 8:74. doi: 10.3389/fnhum.2014.00074

2. Baumeister, R. F., and Leary, M. R. 1995. The need to belong: desire for interpersonal attachments as a fundamental human motivation. Psychol. Bull. 117:497-529.

3. Allen, K.-A. 2020. Psychology of Belonging. Abingdon: Routledge.

4. Kawamoto, T. 2017. What happens in your mind and brain when you are excluded from a social activity? Front. Young Minds 5:46. doi: 10.3389/frym.2017.00046

5. Allen, K., Kern, M. L., Vella-Brodrick, D., Hattie, J., and Waters, L. 2018. What schools need to know about fostering school belonging: a meta-analysis. Educ. Psychol. Rev. 30:1-34. doi: 10.1007/s10648-016-9389-8

6. Organisation for Economic Co-operation and Development (OECD). 2019. PISA 2018 Results (Volume III): What School Life Means for Students' Lives. Paris: OECD. Available online at: https://www.oecd.org/publications/pisa-2018 -results-volume-iii-acd78851-en.htm

7. Allen, K.-A., Kern, M. L., Vella-Brodrick, D., 2018. Understanding the priorities of Australian secondary schools through an analysis of their mission and vision statements. Educ. Admin. Q. 54:249-74. doi: 10.1177/0013161X18758655

8. Allen, K.-A., and Kern, P. 2019. Boosting School Belonging in Adolescents: Interventions for Teachers and Mental Health Professionals. Abingdon: Routledge.

SUBMITTED: 14 January 2020; ACCEPTED: 03 July 2020; PUBLISHED ONLINE: 18 August 2020.

EDITED BY: Valeria Costantino, University of Naples Federico II, Italy 
CITATION: Allen K-A (2020) Do You Feel Like You Belong? Front. Young Minds 8:99. doi: 10.3389/frym.2020.00099

CONFLICT OF INTEREST: The author declares that the research was conducted in the absence of any commercial or financial relationships that could be construed as a potential conflict of interest.

COPYRIGHT () 2020 Allen. This is an open-access article distributed under the terms of the Creative Commons Attribution License (CC BY). The use, distribution or reproduction in other forums is permitted, provided the original author(s) and the copyright owner(s) are credited and that the original publication in this journal is cited, in accordance with accepted academic practice. No use, distribution or reproduction is permitted which does not comply with these terms.

\section{YOUNG REVIEWER}

\section{MATTIA, AGE: 12}

Hello I am Mattia from Italy I am enrolled in second year of Middle School Antonio Sebastiani, Minturno (LT). I am an archer, I like basketball, and I love science. The topic of this article impressed me greatly, because I am a very shy and reserved boy; for this reason I am enjoyed reviewing this article. I thank my mother Barbara lovine, she is a Ph.D. in Molecular biology, for helping me through this experience.

\section{AUTHOR}

\section{KELLY-ANN ALLEN}

Dr. Kelly-Ann Allen is a belonging researcher and endorsed Educational and Developmental Psychologist. She is a senior lecturer in the Faculty of Education at Monash University and Fellow of the College of Educational and Developmental Psychologists. Dr. Allen is also a senior honorary fellow of the Centre for Positive Psychology, Melbourne Graduate School of Education, University of Melbourne. Dr. Allen was previously a school psychologist and developed a great affinity for and love of working with young people. *kelly-ann.allenamonash.edu 